\title{
Ab externo canaloplasty results and efficacy: a retrospective cohort study with a 12-month follow-up
}

\author{
Iraklis Vastardis ${ }^{1 *}$, Sofia Fili ${ }^{1}$, Zisis Gatzioufas ${ }^{2}$ and Markus Kohlhaas ${ }^{1}$
}

\begin{abstract}
Background: The aim of this study is to review the outcomes of canaloplasty versus canaloplasty combined with phacoemulsification in a retrospective cohort study and to evaluate the efficacy of these methods in terms of intraocular pressure (IOP) lowering effect, postoperative complications and additional glaucoma surgery or reintroduction of medical therapy over a 12-month follow-up.
\end{abstract}

Methods: In a retrospective cohort study, 602 eyes with primary open angle glaucoma (POAG) were treated with canaloplasty or canaloplasty combined with phacoemulsification. The results were evaluated separately in two main groups; group A canaloplasty (262 eyes) and group B canaloplasty combined with phaco (322 eyes). Each group was then subdivided into three additional groups according to the severity of glaucoma. The criteria for successful treatment were evaluated between three IOP ranges; IOP $\leq 16 \mathrm{mmHg}, 18 \mathrm{mmHg}$ and $21 \mathrm{mmHg}$. Complete success was considered the percentage of eyes reaching target IOP with no medication and partial success with medication. Groups A and B subgroups were compared using the Kaplan Meier test. Mean IOP, reduction of antiglaucoma agents and additional IOP lowering methods were also evaluated. The follow-up time was 12 months. Statistical significance was set at $p<0.05$.

Results: An incomplete intraoperative cannulation of Schlemm's canal resulting in conversion to other glaucoma surgery occurred in 18 eyes (2.99\%). In both of the main groups, postoperative hyphema, descemet membrane detachment and transient IOP rise were the most common postoperative complications. The mean IOP in group A and subgroups at 12 months was $13.26 \pm 4.5 \mathrm{mmHg}, 15.19 \pm 3.97 \mathrm{mmHg}$ and $18.09 \pm 3.75 \mathrm{mmHg}$. Respectively in group B mean IOP was $14.51 \pm 4.69 \mathrm{mmHg}, 14.40 \pm 4.11 \mathrm{mmHg}$ and $14.25 \pm 2.76 \mathrm{mmHg}$. Complete success was achieved in group A in $69.19,74.51$ and $74.31 \%$ of eyes. In group B complete success was achieved in $81.60,77.33$ and $83.33 \%$ of eyes respectively. Kaplan Meier between groups A and B was statistically significant for $1 O P \leq 16$ $\mathrm{mmHg}$ and IOP $\leq 21 \mathrm{mmHg}(p=0.0041$ and $p=0.0312)$, but not for IOP $\leq 18 \mathrm{mmHg}(p=0.6935)$. Partial success for $\mathrm{IOP} \leq 16 \mathrm{mmHg}$ was 95.23 and $92.26 \%$, for IOP $\leq 18 \mathrm{mmHg}$ was 91.66 and $90.47 \%$ and for $\mathrm{IOP} \leq 21 \mathrm{mmHg}, 90.00$ and $93.10 \%$, in groups A and B respectively. Twenty-three eyes received additional surgery (3.93\%), 10 trabeculectomies and 2 cyclophotocoagulation in group A, and 9 trabeculectomies and 2 cyclophotocoagulation in group B.

Conclusion: Canaloplasty and canaloplasty combined with phacoemulsification significantly lower the IOP and have a lower postoperative complication rate. Additional glaucoma surgery or medication following both procedures is necessary if target IOP is unsatisfactory. In this study, canaloplasty combined with phacoemulsification demonstrated superior success rate compared to canaloplasty alone.

Keywords: Canaloplasty, Schlemm's canal surgery, POAG

\footnotetext{
* Correspondence: vastardis.iraklis@gmail.com

${ }^{1}$ St. Johannes Hospital, Eye clinic, Dortmund, Germany

Full list of author information is available at the end of the article
}

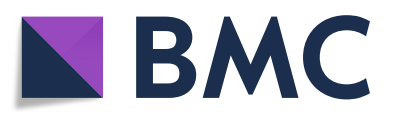

(c) The Author(s). 2019 Open Access This article is distributed under the terms of the Creative Commons Attribution 4.0 International License (http://creativecommons.org/licenses/by/4.0/), which permits unrestricted use, distribution, and reproduction in any medium, provided you give appropriate credit to the original author(s) and the source, provide a link to the Creative Commons license, and indicate if changes were made. The Creative Commons Public Domain Dedication waiver (http://creativecommons.org/publicdomain/zero/1.0/) applies to the data made available in this article, unless otherwise stated. 


\section{Background}

Glaucoma is regarded as one of the major causes leading to blindness in both the developed and developing countries. Recent studies estimate that about 66 million people worldwide are affected with glaucoma, concluding that half of these cases remain undiagnosed [1]. In all cases of people affected with this condition, early diagnosis and sufficient reduction of the intraocular pressure (IOP), either with drug therapy or with surgery, has been proven to reduce rapid progression of visual field defects [2-4]. Drug therapy is administered as the treatment of choice upon diagnosis and early detection of primary open angle glaucoma (POAG) is crucial. Surgery is required when IOP is not manageable with topical therapy or when the socio-economic situation favors it as a tradeoff over years of expensive drug therapies. Trabeculectomy though, is still regarded as the golden standard. It is a filtering operation with excellent results in IOP reduction and is highly cost effective. As a surgical procedure, it relieves IOP by removing part of the eye's trabecular meshwork and adjacent structures to allow drainage of aqueous humor from within the eye to underneath the conjunctiva where it is absorbed. However, its use has been highly correlated with severe, adverse sight threatening complications and difficult post-operative management $[5,6]$. Non penetrating techniques were developed as controlled glaucoma incisional surgery without a full thickness opening. Canaloplasty in particular has been in the spotlight in the recent years as a viable option and considered the evolution of viscocanalostomy $[7,8]$. It is a procedure designed to enhance and restore the eye's natural drainage system and provide sustained reduction of intraocular pressure. After gaining access to Schlemm's canal, a microcatheter is inserted inside and navigated $360^{\circ}$ around it, dilating the main drainage channel and its smaller collector channels through the injection of viscoelastic. The catheter is then removed and a suture is placed within the canal and tightened. Aqueous outflow is restored by tensioning Schlemm's canal with a 10.0 polypropylene suture. In this retrospective cohort study, 602 eyes with POAG were treated with canaloplasty or canaloplasty combined with phacoemulsification. This retrospective study evaluates the results between two groups in three IOP ranges, drug therapy reduction, intraoperative complications and additional IOP lowering methods including surgery in a 12-month follow-up.

\section{Methods}

Between 2010 and 2013, a total of 439 patients already diagnosed with POAG were referred to our clinic for surgery due to uncontrolled IOP despite maximal local and systemic medication, progression of visual field defects or drug therapy intolerance. A total of 602 eyes were initially evaluated and were scheduled to undergo canaloplasty (Group A) or canaloplasty combined with phaco (Group B) due to lens opacity. All patients underwent a baseline standard ophthalmic examination including ophthalmic history with previous ocular surgeries or laser treatments, glaucoma medication use, Humphrey visual field 30-2 SITA Fast test, IOP measurement using Goldmann applanation tonometry, visual acuity testing in decimal Snellen, slit-lamp biomicroscopy for anterior segment evaluation, gonioscopy with angle grading and indirect ophthalmoscopy for fundus assessment. The two main groups were then divided according to the Hodapp, Parrish, Anderson (H-P-A) classification system [9], into three subgroups. Demographics are presented in Table 1. All patients were operated on St. Johannes Hospital Eye Clinic, Dortmund, Germany by MK and written consent was obtained prior to surgery. The tenets of the Declaration of Helsinki were fully respected. The operation was performed ab externo by placing the first flap at 11 o'clock regardless of left or right eye. After preparation of the second scleral flap, access to Schlemm's canal was gained and a microcatheter iTRACK ${ }^{\mathrm{Ti}} 250$ (Ellex Medical Lasers Ltd., 3-4. Second Avenue, Mawson Lakes, SA 5095 Australia) was inserted. Dilation was performed through the injection of sodium hyaluronate, Healon $\mathrm{GV}^{\circ}, 0.85 \mathrm{ml}$ from Abbott (Abbott laboratories, Lake Bluff, Illinois, United States). The microcatheter was then removed and tensioning of the canal with a 10.0 polypropylene suture was performed. Eighteen eyes from both groups were converted to other glaucoma surgery intraoperative due to incomplete cannulation and were excluded from the analysis (Table 1.) Patients remained in our clinic and were discharged at $1.51 \pm 0.5$ days for Group A and $1.48 \pm 0.5$ days for Group B. The post-operative regimen was antibiotics combined with corticosteroids eye drop solution 5 times daily and eye ointment 1 time daily, replaced after 2 weeks with non-corticosteroid anti-inflammatory agents 5 times daily for 2 weeks. Follow up took place at 1 day, 2 weeks, 1 month, 3 months, 6 months and 12 months. Postoperative follow up checks included IOP measurement using Goldmann applanation tonometry, visual acuity testing in decimal Snellen, slit-lamp biomicroscopy for anterior segment evaluation and assessment of complications with decision of subsequent surgical interventions. Humphrey visual field 302 SITA Fast test was repeated again in 12 months. When additional surgery was required, full thickness opening surgery or transscleral diode cyclophotocoagulation were performed due to inadequate IOP lowering effect, failure to comply with medical therapy or both. We did not perform YAG - Goniopuncture in any of the 584 eyes. Trabeculectomy scleral flap was created at 2 o'clock and was combined with mitomycin $0.02 \%$ and ologen ${ }^{\circ}$ 
Table 1 Demographics divided into group A and B and subgroups

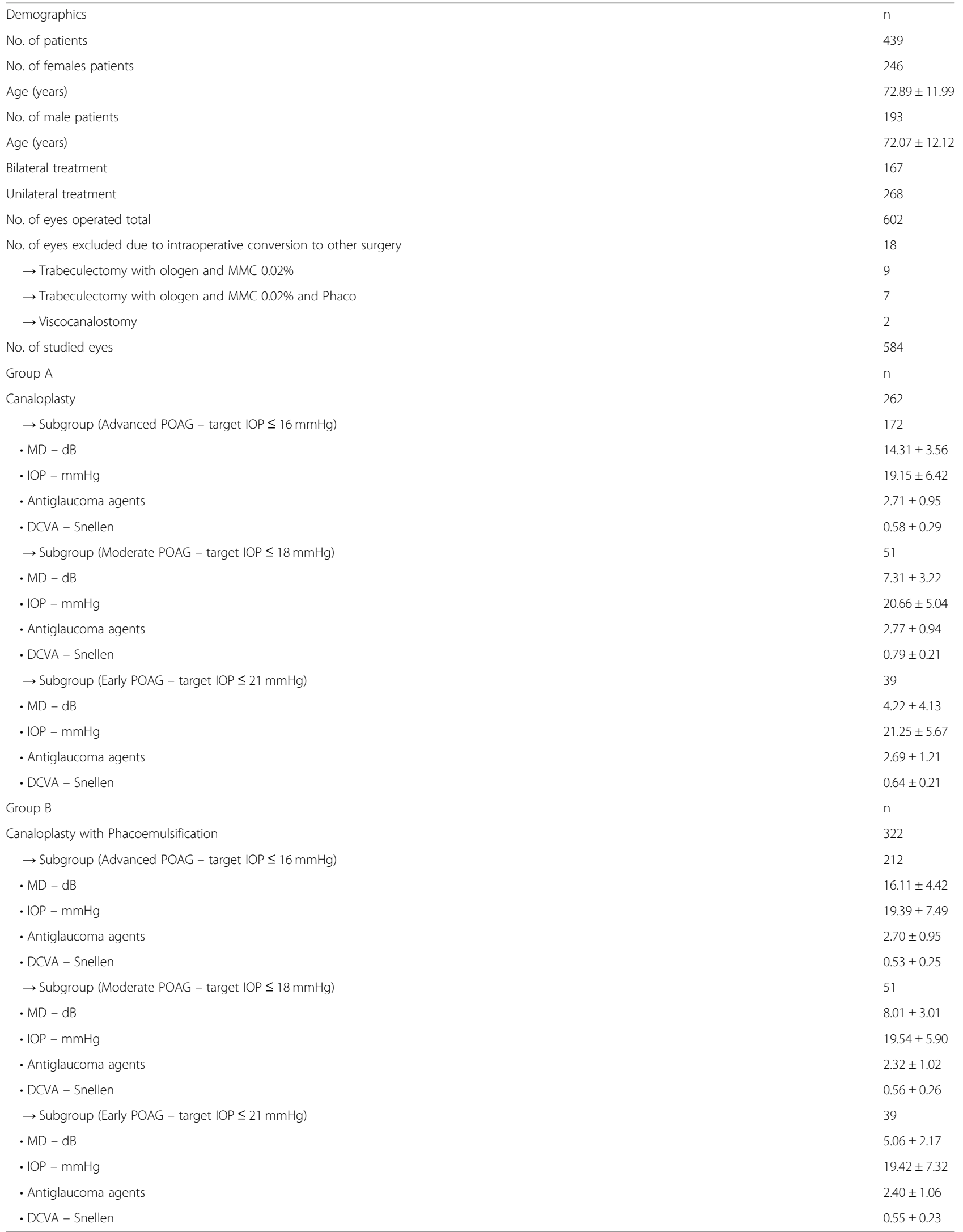


Table 2 Complications divided into group A and B and subgroups

\begin{tabular}{|c|c|c|}
\hline \\
\hline & $\mathrm{n}$ & $\%$ \\
\hline $\begin{array}{l}\text { Sost operative complications } \\
\text { Sroup A } \\
\text { Canaloplasty }\end{array}$ & \multicolumn{2}{|l|}{262} \\
\hline $\begin{array}{l}\text { Canaloplasty } \\
\text { Microhyphem }\end{array}$ & 25 & 9.54 \\
\hline Macrohyphema (> 1.0 mm) & 3 & 1.14 \\
\hline Descemet membrane detachment (DMD) & 6 & 2.29 \\
\hline Hemorrhagic DMD & 0 & 0 \\
\hline Cheese wiring & 1 & 0.38 \\
\hline Anterior chamber inflammation & 0 & 0 \\
\hline Subgroup (Advanced POAG - target IOP $\leq 16 \mathrm{mmHg}$ ) & \multicolumn{2}{|l|}{172} \\
\hline Transient hypotony $(<5 \mathrm{mmHg})$ & 3 & 1.74 \\
\hline Transient hypertony (> 20 mmHg) & 11 & 6.39 \\
\hline $\begin{array}{l}\text { Additional surgery (Trabeculectomy with MMC } 0.02 \% \text { and } \\
\text { ologen) }\end{array}$ & 9 & 5.23 \\
\hline Additional surgery (Cyclophotociagulation) & 2 & 1.16 \\
\hline Subgroup (Moderate POAG - target IOP $\leq 18$ mmHg) & \multicolumn{2}{|l|}{51} \\
\hline Transient hypotony (<5 mmHg) & 0 & 0 \\
\hline Transient hypertony (> 20 mmHg) & 2 & 3.91 \\
\hline $\begin{array}{l}\text { Additional surgery (Trabeculectomy with MMC } 0.02 \% \text { and } \\
\text { ologen) }\end{array}$ & 1 & 1.96 \\
\hline Additional surgery (Cyclophotociagulation) & 0 & 0 \\
\hline Subgroup (Early POAG - target IOP $\leq 21$ mmHg) & \multicolumn{2}{|l|}{39} \\
\hline Transient hypotony (<5 mmHg) & 0 & 0 \\
\hline Transient hypertony (> 25 mmHg) & 6 & 15.38 \\
\hline $\begin{array}{l}\text { Additional surgery (Trabeculectomy with MMC 0.02\% and } \\
\text { ologen) }\end{array}$ & 0 & 0 \\
\hline Additional surgery (Cyclophotociagulation) & 0 & 0 \\
\hline Group B & $n$ & $\%$ \\
\hline Canaloplasty with Phacoemulsification & \multicolumn{2}{|l|}{322} \\
\hline Microhyphema (<1.0 mm) & 13 & 4.03 \\
\hline Macrohyphema (> 1.0 mm) & 2 & 0.62 \\
\hline Descemet membrane detachment (DMD) & 6 & 1.86 \\
\hline Hemorrhagic DMD & 1 & 0.31 \\
\hline Cheese wiring & 0 & 0 \\
\hline Anterior chamber inflammation & 8 & 2.48 \\
\hline Subgroup (Advanced POAG - target IOP $\leq 16 \mathrm{mmHg}$ ) & \multicolumn{2}{|l|}{212} \\
\hline Transient hypotony $(<5 \mathrm{mmHg})$ & 3 & 1.41 \\
\hline Transient hypertony (> 20 mmHg) & 22 & 10.37 \\
\hline $\begin{array}{l}\text { Additional surgery (Trabeculectomy with MMC } 0.02 \% \text { and } \\
\text { ologen) }\end{array}$ & 8 & 3.77 \\
\hline Additional surgery (Cyclophotociagulation) & 2 & 0.62 \\
\hline Subgroup (Moderate POAG - target IOP $\leq 18 \mathrm{mmHg}$ ) & \multicolumn{2}{|l|}{75} \\
\hline Transient hypotony $(<5 \mathrm{mmHg})$ & 1 & 1.33 \\
\hline Transient hypertony (> 20 mmHg) & 8 & 10.66 \\
\hline Additional surgery (Trabeculectomy with MMC $0.02 \%$ and & 1 & 1.33 \\
\hline
\end{tabular}
ologen)
Table 2 Complications divided into group A and B and subgroups (Continued)

\begin{tabular}{lll}
\hline Post operative complications & & \\
\hline Additional surgery (Cyclophotociagulation) & 0 & 0 \\
Subgroup (Early POAG - target IOP $\leq 21 \mathrm{mmHg}$ ) & 35 & \\
Transient hypotony $(<5 \mathrm{mmHg}$ ) & 1 & 2.85 \\
Transient hypertony (> $25 \mathrm{mmHg}$ ) & 3 & 8.57 \\
Additional surgery (Trabeculectomy with MMC 0.02\% and & 0 & 0 \\
ologen) & & \\
Additional surgery (Cyclophotociagulation) & 0 & 0 \\
\hline POAG = primary open angle glaucoma; IOP = intraocular pressure & &
\end{tabular}

Collagen Matrix (Aeon Astron USA Inc.) implantation. Ologen is a biodegradable and implantable porcine extracellular matrix made of atelocollagen cross-linked with glycosaminoglycan, specifically configured to support and modulate tissue repair processes in connective and epithelial ocular tissues. Transcleral diode cyclophotocoagulation was performed in danger of wipe out syndrome or when conjunctiva was limiting the success of full thickness opening surgery. Complete success was regarded as obtaining postoperative $\mathrm{IOP} \leq 21 \mathrm{mmHg}, \leq 18 \mathrm{mmHg}$, and $\leq 16$ $\mathrm{mmHg}$ without medical therapy and partial success an IOP $\leq 21 \mathrm{mmHg}$, $\leq 18 \mathrm{mmHg}$, and $\leq 16 \mathrm{mmHg}$ with medical therapy. Success is reported in the percentage of eyes reaching these goals using the Kaplan Meier test. IOP percentage reduction and medical therapy percentage reduction to baseline was also evaluated. MedCalc was used for statistical purposes and significance was given at $p<0.05$. Regarding distribution, Kolmogorov-Smirnov and chi-squared test were performed. Follow up duration was 12 months. The local institutional review board committee approved this retrospective study.

\section{Results}

A total of 18 eyes (2.99\%) were converted intraoperatively to other procedures and were excluded from the analysis. In total, 584 eyes were analyzed (Table 1). Hyphema, descemet membrane detachment, transient IOP raise or hypotony were among the post-operative complications (Table 2). Mean IOP baseline for group A with target $\mathrm{IOP} \leq 16 \mathrm{mmHg}$ was $19.15 \pm 6.42 \mathrm{mmHg}$ with $2.71 \pm 0.95$ antiglaucoma agents and reduced at 12 months to $13.26 \pm$ $4.50 \mathrm{mmHg}$ with $0.28 \pm 0.99$ agents (Figs. 1 a and 2 a). Medication reduction reached $91.43 \pm 30.74 \%$ (Table 3) and IOP reduction reached $27.88 \pm 29.50 \%$ at 12 months By the end of the follow up, complete success was achieved in $69.19 \%$ and partial success in $95.23 \%$ of cases. Additional surgery was performed in 9 eyes (Table 2). Mean IOP of Group B with target IOP $\leq 16 \mathrm{mmHg}$ was baseline $19.39 \pm 7.49 \mathrm{mmHg}$ with $2.70 \pm 0.95$ antiglaucoma agents and reduced at 12 months to $14.51 \pm 4.69 \mathrm{mmHg}$ with $0.29 \pm 0.87$ (Figs. $1 \mathrm{~b}$ and $2 \mathrm{~b}$ ). Medication reduction 

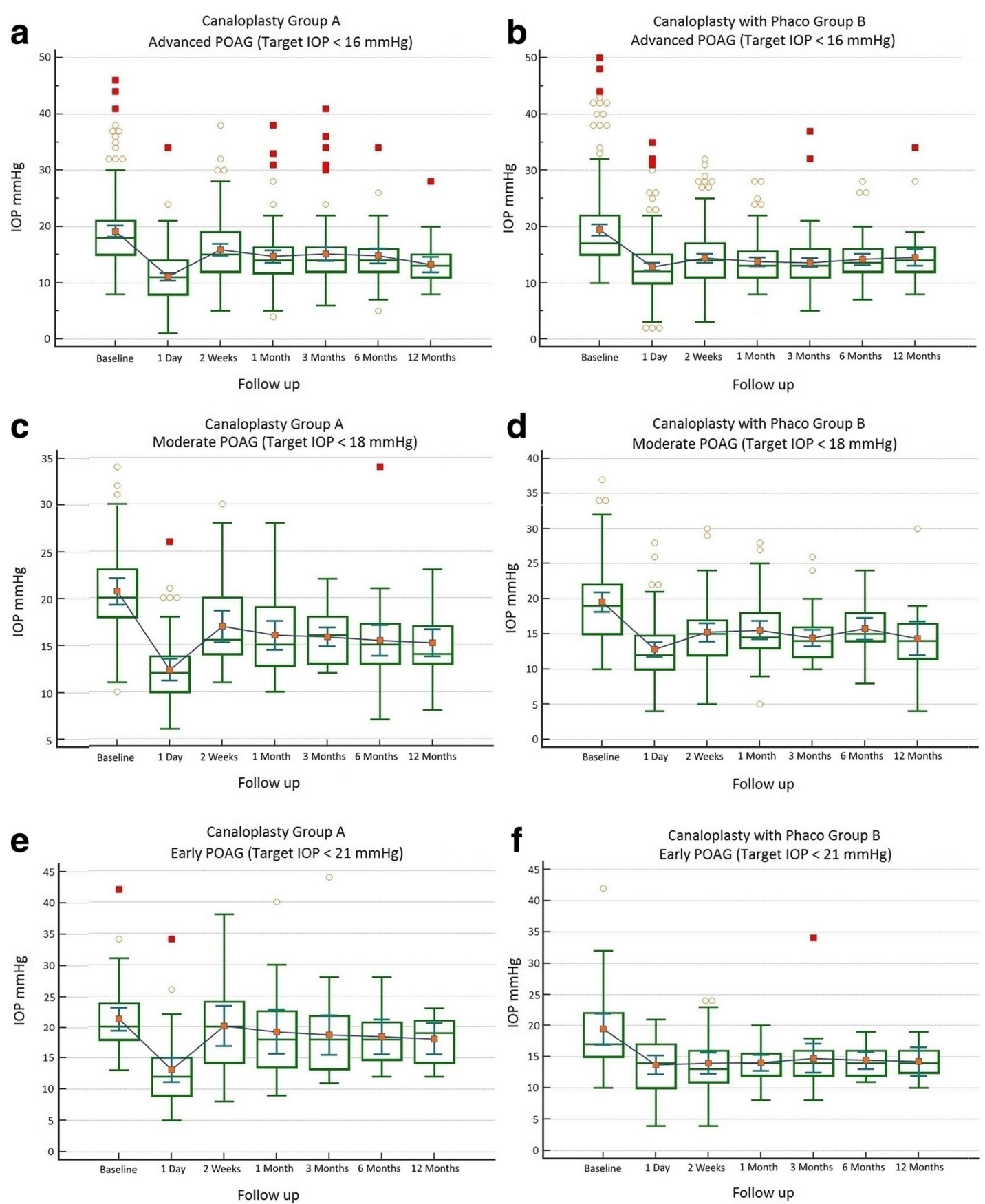

Fig. 1 Reduction of mean IOP from baseline throughout the follow up period. a Group A IOP $\leq 16 \mathrm{mmHg}$; b Group B IOP $\leq 16 \mathrm{mmHg}$; c Group A $\mathrm{IOP} \leq 18 \mathrm{mmHg}$; d Group B IOP $\leq 18 \mathrm{mmHg}$; e Group A IOP $\leq 21 \mathrm{mmHg}$; froup B IOP $\leq 21 \mathrm{mmHg}$

reached $89.43 \pm 29.28 \%$ (Table 3 ) and IOP reduction reached $16.52 \pm 25.37 \%$ at 12 months. By the end of follow up, complete success was achieved in $81.60 \%$ and partial success in $92.26 \%$. Additional surgery was performed in 10 eyes (Table 2). Mean IOP and medication reduction over the 12-month follow-up for both groups with target IOP subgroups was adequate (Figs. 1 a-f and 2 a-f, Table 3). Mean distance corrected visual acuity (DCVA) in group A was stable except from the first day to the first month in most subgroups. Some fluctuations in DCVA between the follow up were due to ocular surface problems (Fig. 3 a,c,e). In group B and subgroups DCVA compared to baseline increased significantly (Fig. 3 b,d,f). Kaplan Meier Log rank test was statistically significant between Group A and B for target IOP $\leq 16 \mathrm{mmHg}$ and target $\mathrm{IOP} \leq 21 \mathrm{mmHg}(p=$ 0.0041 and $p=0.0312$ respectively) (Fig. 4) but was not 

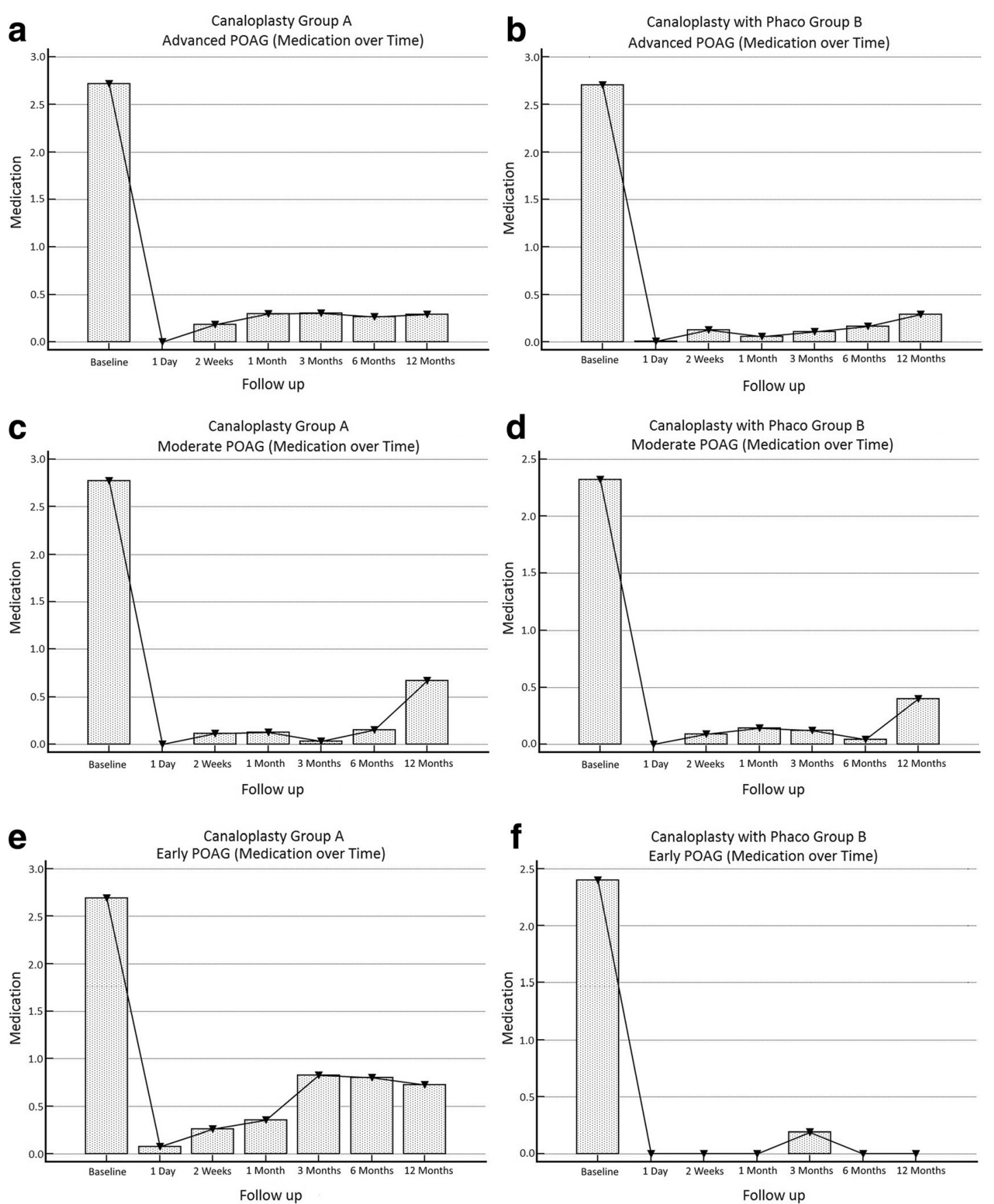

Fig. 2 Reduction of mean antiglaucoma agents from baseline throughout the follow up period. a Group A (advanced POAG - IOP $\leq 16 \mathrm{mmHg}$ ); b Group B (advanced POAG - IOP $\leq 16 \mathrm{mmHg}$ ); c Group A (moderate POAG - IOP $\leq 18 \mathrm{mmHg}$ ); d Group B (moderate POAG - IOP $\leq 18 \mathrm{mmHg}$ ); e Group A (early POAG - IOP $\leq 21 \mathrm{mmHg}$ ); f Group B (early POAG - IOP $\leq 21 \mathrm{mmHg}$ )

significant for target IOP $\leq 18 \mathrm{mmHg}(p=0.6935)$, (Fig. 5). Complete success for IOP $\leq 18 \mathrm{mmHg}$ was achieved in $74.51 \%$ in Group A and in $77.33 \%$ in Group B. Respectively, partial success was 91.66 and $90.47 \%$. In target IOP $\leq 21$ $\mathrm{mmHg}$, complete success for Groups A and B were 74.31 and $83.33 \%$ and partial success 90.00 and $93.10 \%$, respectively. Humphrey visual field 30-2 SITA Fast test at 12 months did not show progression in main groups and subgroups and was not statistically significant (Wilcoxon test $p=0.2541, p<0.3256$ and $p=0.4532$, respectively).

\section{Discussion}

With the advent of canaloplasty in the last decade as a new surgical option in managing IOP in glaucoma 
Table 3 Paired samples t-test of medication percentage reduction in comparison to baseline divided into groups A and B and subgroups throughout the follow up period

\begin{tabular}{|c|c|c|c|c|c|}
\hline $\begin{array}{l}\text { Group A - Medication \% } \\
\text { Advanced POAG }\end{array}$ & $n$ & Mean & Range & SD & $\begin{array}{l}\text { Different }(P<0.05) \\
\text { from factor } \mathrm{nr}\end{array}$ \\
\hline (1) A) Baseline & 172 & 0.00 & 0.0 & \pm 0.00 & $(2)(3)(4)(5)(6)(7)$ \\
\hline (2) B) 1 Day & 172 & -100.00 & $-100.0 /-100.0$ & \pm 0.00 & $(1)(3)(4)(5)(6)(7)$ \\
\hline (3) C) 2 Weeks & 171 & -93.59 & $-100.0 /+50.0$ & \pm 19.94 & $(1)(2)$ \\
\hline (4) D) 1 Month & 161 & -90.38 & $-100.0 /+50.0$ & \pm 26.26 & (1)(2) \\
\hline (5) E) 3 Months & 155 & -89.60 & $-100.0 /+50.0$ & \pm 29.68 & (1)(2) \\
\hline (6) F) 6 Months & 151 & -89.40 & $-100.0 /-100.0$ & \pm 33.84 & (1)(2) \\
\hline (7) G) 12 Months & 168 & -91.43 & $-100.0 /+66.0$ & \pm 30.74 & (1)(2) \\
\hline $\begin{array}{l}\text { Group B - Medication \% } \\
\text { Advanced POAG }\end{array}$ & $n$ & Mean & Range & SD & $\begin{array}{l}\text { Different }(P<0.05) \\
\text { from factor } \mathrm{nr}\end{array}$ \\
\hline (1) A) Baseline & 212 & 0.00 & 0,0 & \pm 0.00 & $(2)(3)(4)(5)(6)(7)$ \\
\hline (2) B) 1 Day & 212 & -99.90 & $-100.0 /-80.0$ & \pm 1.37 & $(1)(3)(5)(6)(7)$ \\
\hline (3) C) 2 Weeks & 187 & -95.56 & $-100.0 /+33.0$ & \pm 18.37 & $(1)(2)(7)$ \\
\hline (4) D) 1 Month & 173 & -97.56 & $-100.0 / 0.0$ & \pm 15.48 & $(1)(7)$ \\
\hline (5) E) 3 Months & 134 & -95.83 & $-100.0 / 0.0$ & \pm 15.85 & $(1)(2)$ \\
\hline (6) F) 6 Months & 132 & -93.78 & $-100.0 / 0.0$ & \pm 21.28 & (1)(2) \\
\hline (7) G) 12 Months & 168 & -89.43 & $-100.0 / 00$ & \pm 29.28 & $(1)(2)(3)(4)$ \\
\hline $\begin{array}{l}\text { Group A - Medication \% } \\
\text { Moderate POAG }\end{array}$ & $n$ & Mean & Range & SD & $\begin{array}{l}\text { Different }(P<0.05) \\
\text { from factor } \mathrm{nr}\end{array}$ \\
\hline (1) A) Baseline & 51 & 0.00 & 0.0 & \pm 0.00 & $(2)(3)(4)(5)(6)(7)$ \\
\hline (2) B) 1 Day & 51 & -100.00 & $-100.0 /-100.0$ & \pm 0.00 & $(1)(7)$ \\
\hline (3) C) 2 Weeks & 50 & -95.45 & $-100.0 /-33.0$ & \pm 15.17 & $(1)(7)$ \\
\hline (4) D) 1 Month & 48 & -95.28 & $-100.0 /-33.0$ & \pm 15.46 & $(1)(7)$ \\
\hline (5) E) 3 Months & 41 & -96.55 & $-100.0 / 0.0$ & \pm 18.56 & $(1)(7)$ \\
\hline (6) F) 6 Months & 39 & -95.96 & $-100.0 /-66.0$ & \pm 10.73 & $(1)(7)$ \\
\hline (7) G) 12 Months & 48 & -76.66 & $-100.0 /+100.0$ & \pm 55.51 & $(1)(2)(3)(4)(5)(6)$ \\
\hline $\begin{array}{l}\text { Group B - Medication \% } \\
\text { Moderate POAG }\end{array}$ & $n$ & Mean & Range & SD & $\begin{array}{l}\text { Different }(P<0.05) \\
\text { from factor } \mathrm{nr}\end{array}$ \\
\hline (1) A) Baseline & 75 & 0.00 & 0.0 & \pm 0.00 & $(2)(3)(4)(5)(6)(7)$ \\
\hline (2) B) 1 Day & 75 & -100.00 & $-100.0 /-100.0$ & \pm 0.00 & $(1)(7)$ \\
\hline (3) C) 2 Weeks & 68 & -96.54 & $-100.0 /-50.0$ & \pm 12.38 & $(1)(7)$ \\
\hline (4) D) 1 Month & 60 & -94.14 & $-100.0 / 0.0$ & \pm 19.42 & $(1)(7)$ \\
\hline (5) E) 3 Months & 55 & -94.30 & $-100.0 / 0.0$ & \pm 22.23 & $(1)(7)$ \\
\hline (6) F) 6 Months & 49 & -98.48 & $-100.0 /-66.0$ & \pm 7.10 & $(1)(7)$ \\
\hline (7) G) 12 Months & 63 & -84.21 & $-100.0 / 0.0$ & \pm 34.00 & $(1)(2)(3)(4)(5)(6)$ \\
\hline $\begin{array}{l}\text { Group A - Medication } \% \downarrow \\
\text { Early POAG }\end{array}$ & $n$ & Mean & Range & SD & $\begin{array}{l}\text { Different }(P<0.05) \\
\text { from factor } \mathrm{nr}\end{array}$ \\
\hline (1) A) Baseline & 39 & 0.00 & 0.0 & \pm 0.00 & $(2)(3)(4)(5)(6)(7)$ \\
\hline (2) B) 1 Day & 39 & -96.15 & $-100.0 /+50.0$ & \pm 24.01 & $(1)(5)(7)$ \\
\hline (3) C) 2 Weeks & 39 & -92.85 & $-100.0 /-50.0$ & \pm 15.43 & (1) \\
\hline (4) D) 1 Month & 34 & -86.76 & $-100.0 / 0.0$ & \pm 28.72 & (1) \\
\hline (5) E) 3 Months & 35 & -72.77 & $-100.0 /+100.0$ & \pm 50.58 & $(1)(2)$ \\
\hline (6) F) 6 Months & 26 & -77.17 & $-100.0 /-20.0$ & \pm 33.04 & (1) \\
\hline (7) G) 12 Months & 30 & -65.15 & $-100.0 /+50.0$ & \pm 50.80 & $(1)(2)$ \\
\hline
\end{tabular}


Table 3 Paired samples t-test of medication percentage reduction in comparison to baseline divided into groups A and B and subgroups throughout the follow up period (Continued)

\begin{tabular}{|c|c|c|c|c|c|}
\hline $\begin{array}{l}\text { Group B - Medication \% } \downarrow \\
\text { Early POAG }\end{array}$ & $n$ & Mean & Range & SD & $\begin{array}{l}\text { Different }(P<0.05) \\
\text { from factor } \mathrm{nr}\end{array}$ \\
\hline (1) A) Baseline & 35 & 0.00 & 0,0 & \pm 0.00 & $(2)(3)(4)(5)(6)(7)$ \\
\hline (2) B) 1 Day & 35 & -100.00 & $-100.0 /-100.0$ & \pm 0.00 & $(1)(5)$ \\
\hline (3) C) 2 Weeks & 30 & -100.00 & $-100.0 /-100.0$ & \pm 0.00 & $(1)(5)$ \\
\hline (4) D) 1 Month & 24 & -100.00 & $-100.0 /-100.0$ & \pm 0.00 & $(1)(5)$ \\
\hline (5) E) 3 Months & 26 & -95.00 & $-100.0 /-50.0$ & \pm 15.38 & $(1)(2)(3)(4)(6)(7)$ \\
\hline (6) F) 6 Months & 28 & -100.00 & $-100.0 /-100.0$ & \pm 0.00 & $(1)(5)$ \\
\hline (7) G) 12 Months & 29 & -100.00 & $-100.0 /-100.0$ & \pm 0.00 & $(1)(5)$ \\
\hline
\end{tabular}

$P O A G=$ primary open angle glaucoma; $S D=$ standard deviation; $n r=$ number $\downarrow$ Reduction of medication percentage

patients, an increasing number of surgeons have started to favor this approach for its safety, efficacy and overall good results. Canaloplasty lowers IOP by a 360-degree viscodilation and tensioning of the Schlemm canal. This procedure is still less likely to be successful in eyes with a nonreversible collapse of collector channels or other outflow pathways that cannot be mechanically enlarged [10]. Episcleral venous pressure and transtrabecular diffusion plays a significant role in the outcomes of canaloplasty procedure. Chanelography and provocative gonioscopy can be used as a tool to predict the outcomes preoperatively [11]. Overall, the efficacy and safety of canaloplasty is well documented [12-19]. In 2011, Grieshaber et al. published the results of a prospective study of 32 White patients with POAG in which the mean IOP dropped from $27.3 \pm 5.6 \mathrm{mmHg}$ preoperatively to $12.8 \pm 1.5 \mathrm{mmHg}$ at 12 months and $13.1 \pm 1.2$ $\mathrm{mmHg}$ at 18 months [12]. They reported a complete success rate for IOP $\leq 21 \mathrm{mmHg}, \leq 18 \mathrm{mmHg}$ and $\leq 16$ $\mathrm{mmHg}$ of $93.8,84.4$ and $74.9 \%$, respectively at 12 months. The same group studied in the same manner African patients and reported a mean IOP at 12 months of $15.4 \pm 5.2 \mathrm{mmHg}$ from baseline of $45.0 \pm 12.1 \mathrm{mmHg}$, reporting a complete success rate for IOP $\leq 21 \mathrm{mmHg}$ of $77.5 \%$ and qualified success rate of $81.6 \%$ at 36 months [13]. In our study, group A showed similar results regarding the mean IOP, which reduced from baseline $19.15 \pm 6.42$ to $13.26 \pm 4.50 \mathrm{mmHg}$ for $\mathrm{IOP} \leq 16 \mathrm{mmHg}$, $20.66 \pm 5.04$ to $15.19 \pm 3.97 \mathrm{mmHg}$ for $\mathrm{IOP} \leq 18 \mathrm{mmHg}$ and $21.25 \pm 5.67$ to $18.09 \pm 3.75 \mathrm{mmHg}$ for $\mathrm{IOP} \leq 21$ $\mathrm{mmHg}$. However, in our study, standard deviation (SD) of mean IOP was significantly higher and our complete success rate was significantly lower with $69.19 \%$ for IOP $\leq 16 \mathrm{mmHg}, 74.51 \%$ for IOP $\leq 18 \mathrm{mmHg}$ and $74.31 \%$ for IOP $\leq 21 \mathrm{mmHg}$. Our partial success rate was significantly higher with 95.23, 91.66 and $90.00 \%$, respectively, and we had a significant reduction of the need for medication in all three subgroups. Bull et al. reported 3-year results investigating the safety and efficacy of canaloplasty in a prospective, multi-center, interventional study of 109 eyes of 109 adult, open-angle glaucoma patients undergoing canaloplasty or combined cataract-canaloplasty surgery. Qualifying preoperative IOPs were at least $16 \mathrm{mmHg}$ with historical IOPs of at least $21 \mathrm{mmHg}$ with or without medical therapy. Eyes with canaloplasty showed a mean baseline IOP of $23.0 \pm 4.3 \mathrm{mmHg}$ and mean glaucoma medication usage of $1.9 \pm 0.7$ medications, which decreased to a mean IOP of $15.1 \pm 3.1 \mathrm{mmHg}$ on $0.9 \pm 0.9$ medications at 3 years postoperatively. Eyes with combined cataract-canaloplasty surgery showed a mean baseline IOP of $24.3 \pm 6.0 \mathrm{mmHg}$ on $1.5 \pm 1.2$ medications, which decreased to a mean IOP of $13.8 \pm 3.2 \mathrm{mmHg}$ on $0.5 \pm 0.7$ medications at 3 years. Intraocular pressure and medication use results for all study eyes were significantly decreased from baseline $(p<0.00001)$ at all intervals. Late postoperative complications included cataracts (19.1\%) and transient IOP elevation (1.8\%) [14]. We demonstrate similar results in groups $\mathrm{A}$ and $\mathrm{B}$ in terms of mean IOP reduction and mean medication reduction (Table 3). We also reported transient IOP elevation in 19 eyes group A (7.25\%) and group B in 33 eyes (10.24\%). These eyes where either treated with medication or with additional surgery if IOP was not manageable (Table 2). Cataract formation following canaloplasty was not reported in group A. Brusini et al. $[15,16]$ reported the midterm results of a multicenter prospective study of 218 eyes from 197 POAG patients with a 23.1 \pm 10.6 month follow up. The mean IOP reduction reported was $44 \%$ from baseline. After 2 years of follow-up, a partial success rate based on postoperative IOP $\leq 21 \mathrm{mmHg}$, $\leq 18 \mathrm{mmHg}$, and $\leq 16 \mathrm{mmHg}$ was 92.1, 84.3 , and $68.5 \%$, respectively, and a complete success for an $\mathrm{IOP} \leq 21 \mathrm{mmHg}, \leq 18 \mathrm{mmHg}$, and $\leq 16 \mathrm{mmHg} 70.8$, 67.4 , and $59.5 \%$, respectively. The number of medications used preoperatively and at the 2-year follow-up was $3.2 \pm 0.9$ and $1.1 \pm 1.3$, respectively. They reported incomplete operations in 20 eyes (9.2\%), hyphema in 47 

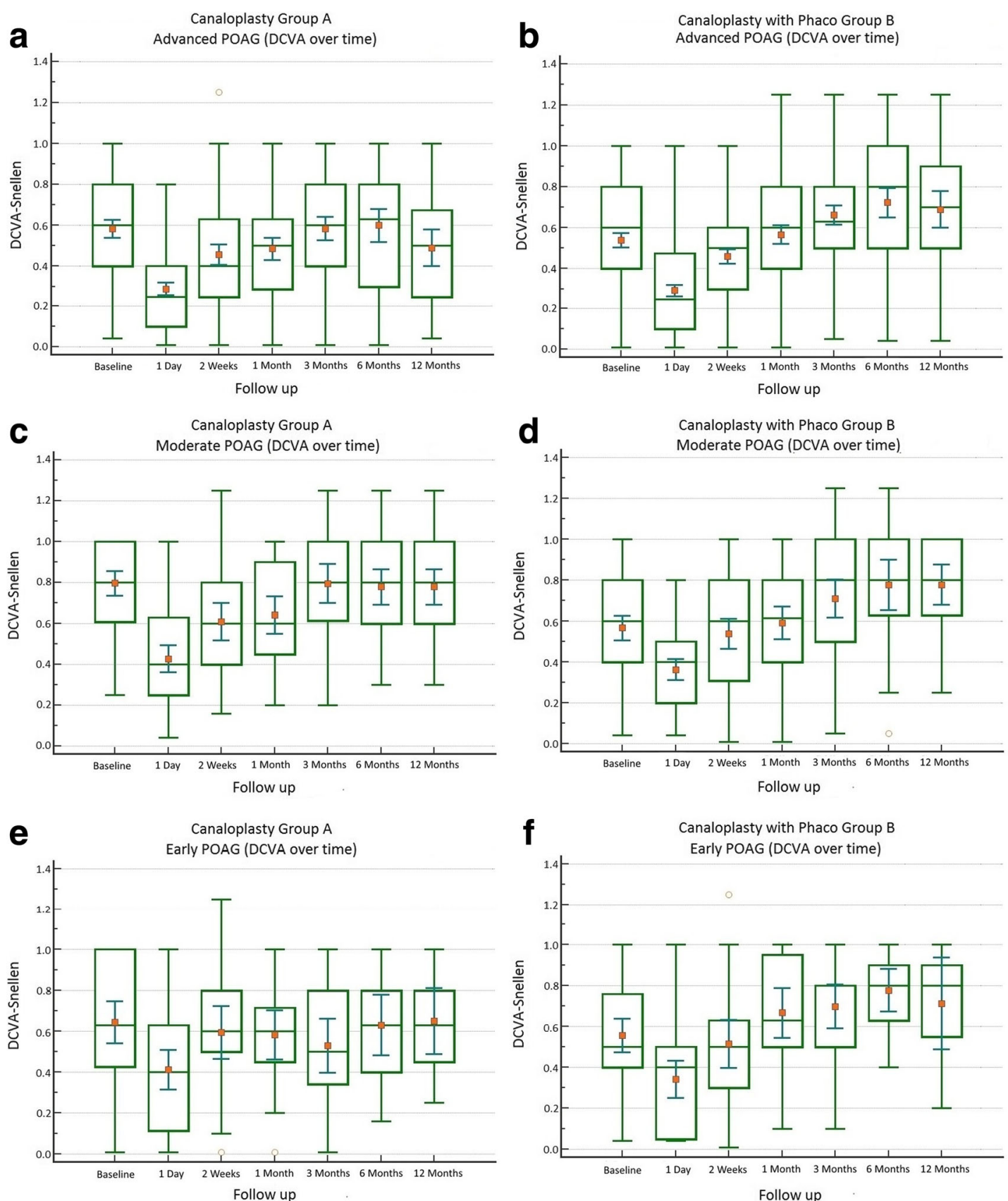

Fig. 3 Fluctuation of mean DCVA in Snellen from baseline throughout the follow up period. a Group A (advanced POAG - IOP $\leq 16 \mathrm{mmHg}$ ); $\mathbf{b}$ Group B (advanced POAG - IOP $\leq 16 \mathrm{mmHg}$ ); c Group A (moderate POAG - IOP $\leq 18 \mathrm{mmHg}$ ); d Group B (moderate POAG - IOP $\leq 18 \mathrm{mmHg}$ ); e Group A (early POAG - IOP $\leq 21 \mathrm{mmHg}$ ); f Group B (early POAG - IOP $\leq 21 \mathrm{mmHg}$ )

eyes (23.7\%), Descemet membrane detachment in 11 eyes (5.5\%), and IOP spikes $>10 \mathrm{mmHg}$ in 12 cases (6.1\%). We reported similar results in both groups A and $\mathrm{B}$ for $\mathrm{IOP} \leq 21 \mathrm{mmHg}$, $\leq 18 \mathrm{mmHg}$, and $\leq 16 \mathrm{mmHg}$, however our follow up was significantly shorter. We excluded 18 eyes originally from the analysis due to incomplete cannulation of Schlemm's canal and conversion to other glaucoma surgery. We had similar post-operative complications but reported over a shorter follow up period. To our knowledge, this study, despite its retrospective nature and the lack of a control group, reports on the largest cohort of eyes that underwent canaloplasty or canaloplasty combined with phacoemulsification. Furthermore, it presents an interesting mix of results that possibly is more reflective of real world practice in comparison to similar studies despite our smaller 


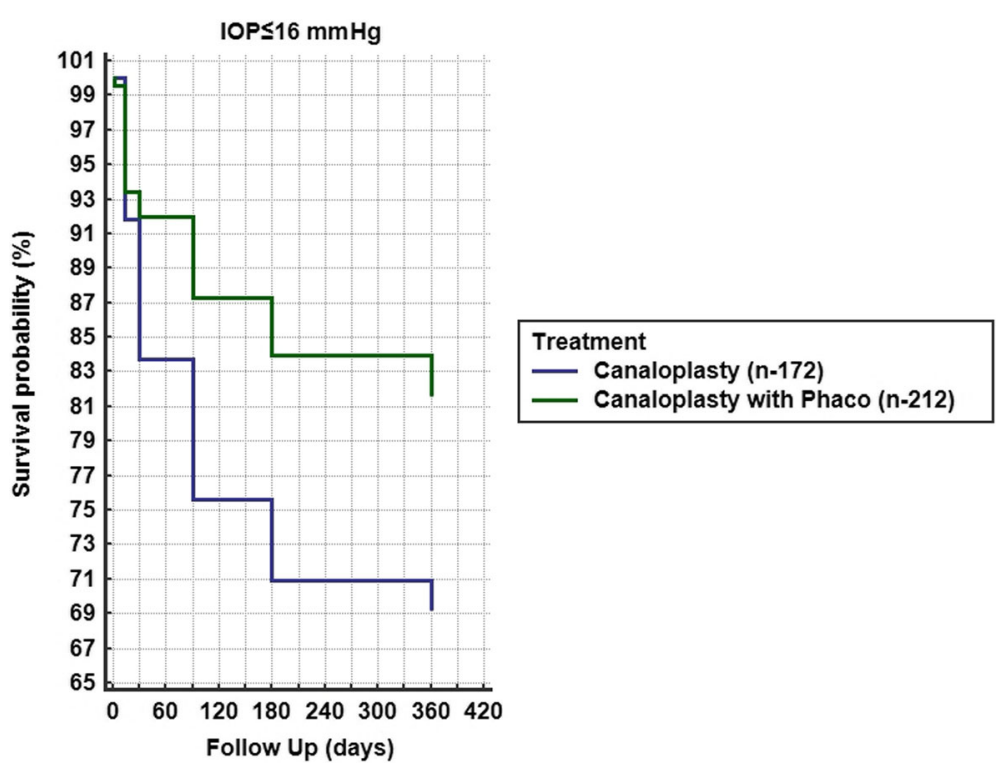

Fig. 4 Kaplan Meier between Groups A and B of complete success, (IOP $\leq 16 \mathrm{mmHg}$, Log rank test $p=0.0041)$

follow up. Our partial success rate was above $90 \%$ in both groups and overall we demonstrated an adequate reduction of mean IOP and reduced post-operative need for medication. Our percentage reduction of IOP was high at 1 day post-op and gradually reduced with one group showing $8 \%$ reduction while other groups showing 16 to $17 \%$ and some groups even above $25 \%$. This could be explained from the low baseline IOP in all our groups that were receiving at baseline up to 5 antiglaucoma agents to maintain IOP, in particular for group A (IOP $\leq$ $21 \mathrm{mmHg}$ ) whose baseline mean IOP with medication was $21.25 \pm 5.67 \mathrm{mmHg}$. The results of this group in comparison to all other groups in all parameters were inferior. We believe that this interesting result was due to failure of collector channels enlargement possibly resulting from increased episcleral venous pressure and decreased transtrabecular diffusion. Nonetheless, the mean IOP of this group was below its target and the medication reduced from $2.69 \pm 1.2$ to $0.72 \pm 1.0$ at 12 months, a reduction of $65.15 \pm 50.80 \%$ from baseline. Between groups $\mathrm{A}$ and $\mathrm{B}$, the results were superior in most parameters for group B, showing that canaloplasty with

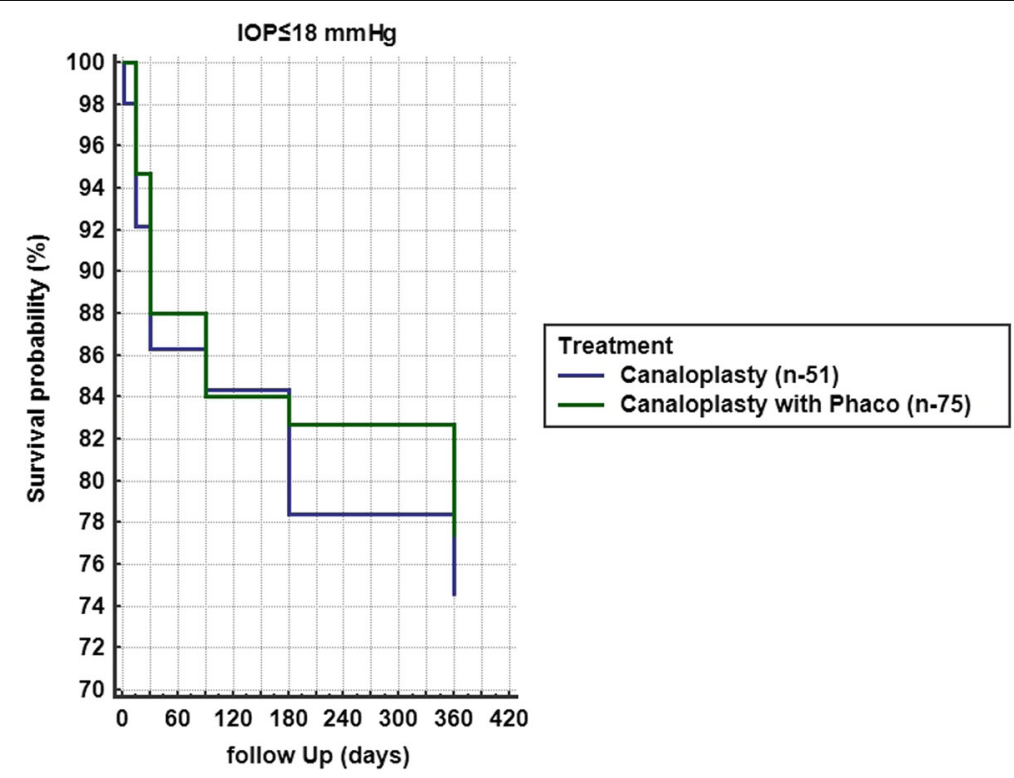

Fig. 5 Kaplan Meier between Groups A and B of complete success, (IOP $\leq 18 \mathrm{mmHg}$, Log rank test $p=0.6935)$ 
phaco provides better outcomes as shown in other studies [14, 17-19]. Overall, we reported acceptable complete and partial success rates and managed to surgically reduce IOP with minor complications and a few additional surgical interventions.

\section{Conclusions}

Overall, canaloplasty alone and canaloplasty combined with phacoemulsification are safe surgical procedures that significantly reduce IOP in POAG. An incomplete intraoperative cannulation of Schlemm's canal can result in conversion to other glaucoma surgery. The most common post-operative complications are hyphema, DMD, hypotony and transient IOP elevation that requires additional medication and possibly surgical intervention if medication fails. Canaloplasty combined with phacoemulsification provided superior results in terms of achieving the target IOP with no additional medication in comparison to canaloplasty alone.

\section{Acknowledgments}

Dr. Clifford Lamptey specialist registrar in the republic of Ireland, MB, Bch BAO LRPC\&SI NUI (Hons), MRCS, MRCPsych MICGP for proofreading and grammatical corrections.

\section{Funding}

Not applicable.

\section{Availability of data and materials}

Not applicable.

\section{Authors' contributions}

IV Writing, editing and statistical analysis. SF Data assembly and preparation. ZG Supervising statistics. MK General supervising, surgical interventions. All authors read and approved the final manuscript.

\section{Competing interests}

The authors declare that they have no competing interests.

\section{Author details}

'St. Johannes Hospital, Eye clinic, Dortmund, Germany. ${ }^{2}$ Basel University Hospital, Eye Clinic, Basel, Switzerland.

Received: 28 August 2018 Accepted: 22 February 2019

Published online: 12 March 2019

\section{References}

1. Quigley HA. Number of people with glaucoma worldwide. Br J Ophthalmol. 1996;80(5):389-93.

2. Heijl A, Leske MC, Bengtsson B, Hyman L, Bengtsson B, Hussein M, et al. Reduction of intraocular pressure and glaucoma progression: results from the Early Manifest Glaucoma Trial. Arch Ophthalmol. 2002;120(10):1268-79.

3. Kass MA, Heuer DK, Higginbotham EJ, Johnson CA, Keltner JL, Miller JP, et al. The Ocular Hypertension Treatment Study: a randomized trial determines that topical ocular hypotensive medication delays or prevents the onset of primary open-angle glaucoma. Arch Ophthalmol. 2002;120(6):701-13; discussion 829-30.

4. Lichter PR, Musch DC, Gillespie BW, Guire KE, Janz NK, Wren PA, et al. Interim clinical outcomes in the Collaborative Initial Glaucoma Treatment Study comparing initial treatment randomized to medications or surgery. Ophthalmology. 2001;108(11):1943-53.

5. Prasad N, Latina MA. Blebitis and endophthalmitis after glaucoma filtering surgery. Int Ophthalmol Clin. 2007;47(2):85-97.

6. Zahid S, Musch DC, Niziol LM, Lichter PR. Collaborative initial Glaucoma treatment study group. Risk of endophthalmitis and other long-term complications of trabeculectomy in the Collaborative Initial Glaucoma Treatment Study (CIGTS). Am J Ophthalmol. 2013;155(4):674-80.

7. Stegmann R. Visco-canalostomy: a new surgical technique for open angle glaucoma. Annals de Istituto Barraquer. 1995;25:229-32.

8. Lewis RA, von Wolff K, Tetz M, Koerber N, Kearney JR, Shingleton BJ, et al. Canaloplasty: circumferential viscodilation and tensioning of Schlemm canal using a flexible microcatheter for the treatment of open-angle glaucoma in adults: two-year interim clinical study results. J Cataract Refract Surg. 2009; 35(5):814-24.

9. Hodapp E, Parrish RK II, Anderson DR. Clinical decisions in glaucoma. St Louis: The CV Mosby Co; 1993. p. 52-61.

10. Cagini C, Peruzzi C, Fiore T, Spadea L, Lippera M, Lippera S. Canaloplasty: current value in the management of glaucoma. J Ophthalmol. 2016;2016: 7080475.

11. Grieshaber MC. Chanelography and mechanism of action in canaloplasty. Ophthalmologe. 2015;112(4):319-24.

12. Grieshaber MC, FraenkI S, Schoetzau A, Flammer J, Orgül S. Circumferential viscocanalostomy and suture canal distension (canaloplasty) for whites with open-angle glaucoma. J Glaucoma. 2011;20(5):298-302.

13. Grieshaber MC, Pienaar A, Olivier J, Stegmann R. Canaloplasty for primary open angle glaucoma: long term outcome. Br J Ophthalmol. 2010;94:1478-82.

14. Bull H, von Wolff K, Körber N, Tetz M. Three-year canaloplasty outcomes for the treatment of open-angle glaucoma: European study results. Graefes Arch Clin Exp Ophthalmol. 2011;249(10):1537-45.

15. Brusini P, Caramello G, Benedetti S, Tosoni C. Canaloplasty in open-angle glaucoma: mid-term results from a multicenter study. J Glaucoma. 2016; 25(5):403-7.

16. Brusini P. Canaloplasty in open-angle glaucoma surgery: a four-year followup. Sci World J. 2014;2014:7. Article ID 469609. https://doi.org/10.1155/2014/ 469609.

17. Lewis RA, von Wolff K, Tetz M, Koerber N, Kearney JR, Shingleton BJ, et al. Canaloplasty: three-year results of circumferential viscodilation and tensioning of Schlemm canal using a microcatheter to treat open-angle glaucoma. J Cataract Refract Surg. 2011;37(4):682-90.

18. Khaimi MA, Dvorak JD, Ding K. An analysis of 3-year outcomes following canaloplasty for the treatment of open-angle glaucoma. J Ophthalmol. 2017:2017:2904272.

19. Tetz M, Koerber N, Shingleton BJ, von Wolff K, Bull H, Samuelson TW, et al. Phacoemulsification and intraocular lens implantation before, during, or after canaloplasty in eyes with open-angle glaucoma: 3-year results. J Glaucoma. 2015;24(3):187-94.
Ready to submit your research? Choose BMC and benefit from:

- fast, convenient online submission

- thorough peer review by experienced researchers in your field

- rapid publication on acceptance

- support for research data, including large and complex data types

- gold Open Access which fosters wider collaboration and increased citations

- maximum visibility for your research: over $100 \mathrm{M}$ website views per year

At $\mathrm{BMC}$, research is always in progress.

Learn more biomedcentral.com/submissions 